\title{
Cinismo y QUINISMO: DOS ACTITUDES EN LA CONCEPCIÓN DE LAS LENGUAS EN CATALUÑA
}

\author{
Daniel Pinto Pajares \\ Universidad de Vigo \\ danielpinto_92@hotmail.es
}

\begin{abstract}
Resumen
El cinismo y el quinismo son actitudes antitéticas que pueden materializarse discursivamente a través del grado de opinión de la modalidad epistémica. En este trabajo proponemos cuatro enunciados arquetípicos que representan múltiples opiniones respecto a la idoneidad o inconveniencia de que el catalán y el castellano acaparen los espacios y usos sociolingüísticos en Cataluña y en las cuales están presentes los componentes cínico y quinico. Estos elementos, que privilegian a una u otra lengua, no aparecen aisladamente, sino que se da una lucha entre ambas actitudes en la que una de ellas matiza la efectividad de la otra. Tomamos la perspectiva del Análisis Crítico del Discurso porque las ideologías que reproducen las relaciones de poder entre las lenguas se manifiestan discursivamente. Mediante esta perspectiva, dividimos los enunciados en segmentos separados ideológicamente y señalamos cuál de ellos se ha de atacar para construir ideologías lingüísticas favorables a la lengua minorizada.

Palabras clave: modalidad epistémica; Análisis Crítico del Discurso; ideología lingüística; tríada discursiva; catalán
\end{abstract}

Title: Cynisism and kynicism: two attitudes that lead to the comprehension of languages in Catalonia

\begin{abstract}
Cynicism and kynicism are antithetical attitudes which can discursively materialize through the opinion degree of the epistemic modality. In this paper, we propose four archetypical statements representing several opinions regarding the suitability and inconvenience of Spanish and Catalan languages about how they compete to monopolize sociolinguistic domains and uses in Catalonia. Cynical or kynical components are made clear in these sentences. These elements, which favour one or another language, do not appear in isolation, but there is a struggle between both attitudes in which one of them nuance the effectiveness of the other one. We take the Critical Discourse Analysis since the ideologies which reproduce the power relations between languages reveal themselves discursively. Through this perspective, we divide the sentences into ideologically separated segments and we point out which of them must be attacked to build favourable linguistic ideologies to the minoritized language.

Keywords: epistemic modality; Critical Discourse Analysis; linguistic ideology; discursive triad; Catalan language
\end{abstract}




\section{INTRODUCCIÓN}

Las tensiones entre las distintas lenguas e idiosincrasias de España han derivado en el progresivo fortalecimiento del castellano como lengua hegemónica frente a las lenguas de los territorios periféricos. La etapa histórica que mejor representa esta tradición, el franquismo, es de sobra conocida por la imposición del castellano y la persecución y prohibición de todo rasgo de diversidad lingüística y cultural. En el caso que nos ocupa, el catalán había estado ligado a una burguesía local pujante desde el siglo XIX, por lo que el franquismo no consiguió desvincular la lengua y la conciencia nacional catalanas de la perspectiva de progreso socioeconómico (Dowling, 2013).

Tras la muerte de Franco en 1975, España entra en un periodo transitorio para homologar el Estado a las demás democracias europeas. En 1978 se ratifica la nueva Constitución que pretende consensuar las distintas tendencias políticas y nacionales. Este texto otorga al castellano la oficialidad en todo el Estado y abre la puerta a que las distintas Comunidades Autónomas legislen sobre sus lenguas propias. En Cataluña, el Estatuto de Autonomía de 1979 garantiza la oficialidad y el uso normalizado del catalán y del castellano.

Inmediatamente, los órganos legislativos de Cataluña ponen en marcha una serie de medidas de política lingüística con las que promocionar el conocimiento y el uso del catalán y revertir la brecha generacional, la merma de la cultura escrita y la práctica social de la lengua (Iglésias, 2019). En estos años, si bien el 97\% de los nativos de Cataluña afirmaba utilizar el catalán en sus interacciones cotidianas, el principal escollo al que se enfrenta el proceso de normalización lingüística es el alto ratio de inmigración procedente de territorios castellanohablantes instalados en las periferias urbanas ante la progresiva industrialización (Shabad y Gunther, 1982). En la década de 1980, las áreas de segundas coronas metropolitanas de Cataluña concentran una alta proporción de inmigrantes de primera y segunda generación fundamentalmente castellanohablantes y solo aproximadamente un tercio de los cuales recibe mensajes en catalán y reproduce prácticas lingüísticas en esta lengua con mayor o menor intensidad (Bastardas, 1986).

Los resultados de esta política han resultado beneficiosos para la vitalidad del catalán en las últimas décadas: ha aumentado el número de escuelas que ofrece inmersión lingüística en catalán, se ha desarrollado terminología moderna gracias a diversas instituciones filológicas, la administración pública de Cataluña emplea el catalán como lengua prioritaria y existen medios de comunicación en catalán, entre otros éxitos (Mar-Molinero, 1994).

¿Por qué, entonces, asumimos el catalán como una lengua minorizada si, a la vista de lo expuesto anteriormente, cuenta con protección oficial y con un proceso 
potente de normalización lingüística? El compromiso de las instituciones públicas de Cataluña parece incuestionable, pero los usos reales de la población sugieren tendencias por las que la competencia con el castellano hace decrecer su dominio.

La Enquesta d'Usos Lingüistics de la Població 2018 (Idescat, 2019) aporta datos reveladores de la situación sociolingüística en Cataluña. Entre otros, la elección lingüística en el pequeño y gran comercio pierde paulatinamente usos exclusivos en catalán en favor del bilingüismo; las habilidades orales y escritas siguen alcanzando cotas más altas en castellano que en catalán, con una diferencia de hasta 32,3 puntos porcentuales en favor del castellano respecto al conocimiento de la lengua escrita; el $56,4 \%$ de la población no tiene interés en aprender el catalán o en mejorar sus capacidades.

Un dato sintomático se encuentra en la elección lingüística cuando una persona se dirige a un interlocutor en catalán y este le responde en castellano. La tendencia mostrada en la última década es la pérdida de interlocutores que siguen la conversación en catalán, mientras que esta actitud no se reproduce en el caso inverso: cuando una persona se dirige a otra en castellano y esta última responde en catalán, existe una mayor proporción de hablantes que se mantienen en el castellano. Esta convergencia lingüística se ha detectado desde la década de 1970. La lengua utilizada por grupos etnolingüísticos heterogéneos dependía de la competencia lingüística de los interlocutores castellanohablantes y de su proporción con respecto a los catalanohablantes en el acto comunicativo (Calsamiglia y Tusón, 1980). No obstante, estudios posteriores como el de Boix (1993) daban pie a una interpretación más amplia por la que las elecciones lingüísticas en grupos heterogéneos favorecían al catalán cuando los contextos de comunicación eran percibidos como institucionalizados y propensos al catalán.

Actitudes que conducen a la interpretación del castellano como lengua por defecto han sido señaladas en investigaciones como la de Boix y De Rosselló (2003), que subrayan la predilección del alumnado de la Universitat de Barcelona por sustituir el catalán por el castellano cuando hay alumnado extranjero en el aula, y en Bretxa y Vila i Moreno (2012), que detectan un descenso en el uso del catalán en el paso de la educación Primaria a la Secundaria en favor del bilingüismo, por lo que la potenciación del bilingüismo no conlleva un aumento del uso social del catalán.

Estas relaciones de desigualdad que convierten al catalán en la lengua minorizada de Cataluña son proyectadas por estructuras de poder y se plasman discursivamente. En este trabajo adoptamos el enfoque del Análisis Crítico del Discurso - en adelante $\mathrm{ACD}$ - para investigar las ideologías lingüísticas que contribuyen a sostener o a combatir las relaciones asimétricas entre el castellano y el catalán. Para 
van Dijk, «el ACD está relacionado con el poder y el abuso de poder y cómo estos son producidos por el texto y el habla» (2004: 11). El ACD analiza las formas discursivas creadas por los grupos dominantes para averiguar cómo mantienen y reproducen relaciones de desigualdad en la sociedad, del mismo modo que centra su atención en la oposición discursiva de los grupos dominados por esta desigualdad. La orientación del posicionamiento personal del hablante implica conceder a una $\mathrm{u}$ otra lengua el privilegio de aparición en los diferentes espacios y usos sociales. Sin embargo, las ideologías que transmiten los sujetos no son del todo uniformes a nivel discursivo, puesto que la modalidad epistémica encarna un contraste entre dos conceptos: el cinismo y el quinismo (Sloterdijk, 1989).

Nuestro objetivo es aportar un marco analítico de los discursos construidos mediante el grado de opinión de la modalidad epistémica y aplicarlo a los discursos que giran en torno a la idoneidad e inconveniencia de que el castellano y el catalán predominen en los distintos usos y espacios sociales de Cataluña. Establecemos cuatro esquemas arquetípicos de análisis discursivo diseñados para este propósito que ayuden a localizar los diferentes componentes cuya carga ideológica es antitética. La segmentación del discurso permite localizar la impronta de las ideologías que favorecen el dominio del castellano pues, según cada estructura enunciativa, adquieren diferentes localizaciones. Conviene señalar que no pretendemos establecer un análisis exhaustivo de ejemplos concretos que aludan a contextos políticos, sociales o de otra índole. Más bien, nuestra intención es establecer una serie de esquemas que sirvan para localizar la impronta ideológica en diferentes partes del discurso, de modo que sea fácilmente reconocible el componente discursivo que es necesario potenciar para fomentar una ideología favorable hacia la revitalización del catalán.

\section{Cinismo y Quinismo}

El filósofo alemán Peter Sloterdijk desarrolló en su Crítica de la razón cínica (1989) una revisión crítica de la sociedad moderna en la que impera una «falsa conciencia ilustrada» (1989: 40) que la lleva a un estado de cinismo. Esta actitud se presenta en los individuos que, aun siendo conscientes de las desigualdades sociales, se muestran conformistas con la realidad asumiendo lo que se ha venido en llamar «mimetismo autoconsciente» (1989: 43). Pese a conocer las implicaciones negativas en el escenario público que pueden contener las opiniones que manifiestan, los individuos las sostienen sin reparo para garantizar su felicidad. Sloterdijk recoge esta idea en su célebre aforismo «saben lo que hacen, pero lo 
hacen porque las presiones de las cosas y el instinto de autoconservación [...] les dicen que así tiene que ser» (1989: 40). El cinismo es una falsa conciencia que «saca la conclusión de las "experiencias malas" de todos los tiempos, y solo hace valer la indiferencia sin perspectiva de la cruda realidad» (1989: 762). Aunque el sujeto cínico es consciente de las estructuras de poder, cabe esperar el triunfo de la ideología dominante sobre las racionalidades contrahegemónicas a causa de la paralización de la razón. Este triunfo es lo que denominamos «ritual cínico», que entendemos como la pulsión de la ideología dominante que lleva a un individuo a actuar en consonancia al orden normativo hegemónico.

En este punto, si bien se podría presumir que no existe lugar para la contestación, dado que todo el engranaje socio-ideológico parece estar determinado a satisfacer los objetivos de la clase dominante, Sloterdijk (1989) no concede una integridad exclusiva del cinismo sobre toda la población, sino que sugiere una tensión entre el cinismo y su contrario, el quinismo. El autor entiende este concepto como un comportamiento que, sin implicar ineludiblemente una crítica insolente y estruendosa contra el cinismo, es coherente entre las esferas privada y pública del sujeto. El quinismo se concibe como un equilibrio entre las creencias que construyen los entendimientos personales y las acciones públicas derivadas de ellas. Mientras que el cinismo induciría a vivir de una manera opuesta a la que se piensa, el quinismo impulsaría la coherencia entre las creencias y las acciones. $\mathrm{Si}$ anteriormente aludimos al ritual cínico como la pulsión de la ideología dominante, en este caso introducimos el concepto de «conocimiento quinico» al que nos referiremos a lo largo del trabajo. Este elemento representa las racionalidades de los hablantes sobre el orden normativo existente que les lleva a tomar consciencia ante la minorización lingüística y responsabilizarse mediante sus prácticas discursivas, a pesar de que sus comportamientos contravengan el orden social e ideológico imperante.

En la obra de Sloterdijk (1989), la conceptualización que se acaba de presentar no tiene una aplicación directa sobre los fenómenos lingüísticos. Más bien, los trabajos centrados en las aplicaciones prácticas del cinismo y el quinismo se refieren al impacto de la ironía y el sarcasmo en los discursos culturales y políticos (Allan, 2004). Consecuentemente, consideramos novedoso trasladar esta teorización a la investigación de un fenómeno sociolingüístico como lo es el conflicto entre lenguas dominantes y minorizadas. El horizonte epistemológico de los conceptos descritos anteriormente brinda la posibilidad de ampliar el marco explicativo que proponemos en este trabajo. 


\section{LA TRÍADA DISCURSIVA}

En tanto que mecanismos que toman partido por visiones del mundo e ideologías determinadas, ciertas instituciones y formas de estructuración de la sociedad no son neutrales y su sesgo ideológico queda plasmado cultural y discursivamente en lo que se puede decir y lo que no, lo que es moralmente aceptable y censurable. Estos procesos de configuración social no pueden entenderse sin acudir a las modificaciones en las prácticas discursivas de los hablantes, pues las ideologías derivadas de la interacción social contribuyen a mantener relaciones de poder (Fairclough, 2003). El statu quo parecería, por tanto, asegurado a través de los mecanismos discursivos, pero otros autores representantes del ACD destacan la relativización de esta legitimación. Wodak et al. (2009) señalan que el discurso es constitutivo de la sociedad en múltiples macrofunciones, de modo que el discurso no solo sería responsable de construir y perpetuar un orden social desigual, sino que también reúne estrategias de transformación y desmantelamiento en favor de grupos sociales contrarios o alejados del orden normativo. Por consiguiente, entendemos la potencialidad del discurso como legitimadora de un orden desigual, pero también como disruptiva y articuladora de nuevas configuraciones.

Van Dijk ha utilizado la etiqueta «socio-cognitivo» (2001: 97) para calificar el tipo de ACD que realiza y que, precisamente, alude a la característica tríada discurso-cognición-sociedad que propone. Para este autor (ibid), el discurso está compuesto por tres elementos: (i) el propio discurso es entendido como un acontecimiento interaccional en sus formas oral y escrita; (ii) la cognición se refiere a cualquier proceso mental que interviene en el discurso, como las creencias, las evaluaciones y las emociones; y (iii) la sociedad es asumida como el conjunto de microestructuras que tienen lugar en las interacciones directas, así como las macroestructuras societales que definen y delimitan grupos sociales, políticos, culturales o étnicos, entre otros.

En nuestro caso, analizamos construcciones discursivas arquetípicas en las que se ponen en relación el castellano como lengua dominante y el catalán como lengua minorizada en su pugna por acaparar el escenario sociolingüístico de Cataluña. En estas proposiciones, se detectan los tres elementos de la tríada discursiva de van Dijk (2001) para focalizar la atención en el componente que contiene la pulsión cínica de la ideología dominante y saber cómo atacarla. Ciertos enunciados reflejan la convicción cínica de un individuo ante la idoneidad de que un espacio o uso sea ocupado por el castellano, a la vez que se desprende la influencia quínica a través de la modalidad epistémica que le lleva a suavizar su aserción para no dañar al catalán. Paralelamente, otras oraciones propuestas implican un posicionamiento quinico y 
positivo hacia los usos y espacios reservados para el catalán, pero este se ve matizado por la pulsión cínica de la ideología dominante.

\section{LA MODALIDAD EPISTÉMICA EN EL GRADO DE OPINIÓN}

El discurso oral y escrito presenta marcas ideológicas que revelan el posicionamiento de las personas enunciadoras con respecto a sus mensajes. La modalización discursiva ha dado lugar a diferentes interpretaciones y clasificaciones, pero en todo caso alude a «la actitud del sujeto hablante ante el oyente y/o ante el contenido de la predicación emitida por él en el enunciado» (Otaola Olano, 1988: 99).

La certeza y la opinión son posicionamientos adoptados por los hablantes y expresados gramaticalmente, pero existe una polarización en estos ejes que implica escalas graduales. Para Halliday y Matthiessen (2014), la polaridad gira en torno al sí y al no de la validez de la predicación, puesto que la veracidad o la falsedad no dependen del enunciado sino de los consensos acordados socialmente.

En este trabajo construimos una serie de oraciones con la modalidad epistémica, que se refiere al nivel de compromiso que el emisor asume respecto a la veracidad y certeza de su discurso (Fairclough, 2003). En el estudio de la modalidad epistémica, se han propuesto numerosos grados situados entre un polo máximo que denota la total seguridad y un polo mínimo en el que se expresan serias dudas respecto a la factualidad que expresa el enunciado. Entre ambos extremos cabe una serie de posiciones intermedias que no siempre están claras en el estudio de la modalidad epistémica. En todo caso, existe cierto consenso a establecer, al menos, las siguientes tres categorías: certeza, probabilidad y posibilidad (Halliday y Matthiessen, 2014).

Concretamente, en este trabajo tomamos el nivel de la opinión, cuya veracidad no se puede certificar en tanto que el criterio epistémico no actúa sobre su validación. En este sentido, algunos autores separan las opiniones y las creencias de cualquier forma de conocimiento tales como los juicios de hecho, dado que estos sí disponen de métodos por los que su contenido se verifica (van Dijk, 2006). Sin embargo, este motivo no es suficiente para sentenciar que las opiniones sean juicios falsos, puesto que las proposiciones subjetivas con las que se expresan las creencias no dan información sobre la realidad, sino sobre el individuo que percibe sensorialmente esa realidad y que está limitado por su propia naturaleza y estado de conciencia (Laserna, 1985).

Las técnicas para expresar opinión son variadas en castellano. En nuestro caso, hemos elegido un verbo de actitud proposicional, el verbo creer, considerado prototípico de este género y que permite construir proposiciones básicas con un referente 
que representa la entidad correferencial que sostiene una opinión determinada, la cual se desarrolla en el segundo elemento de la oración en forma de subordinada sustantiva (de Saeger, 2006).

En la literatura académica, este verbo tiene dos interpretaciones semánticas: creencia o evidencia insuficiente y opinión y actitud personal (Arndt, 1987; Comesaña, 2002; de Saeger, 2006). Estas dos funciones están vinculadas a una posición sintáctica y una realización prosódica determinadas. La tendencia en castellano es elidir el sujeto pronominal dado que su identificación es clara mediante las desinencias verbales. No obstante, la variación formal determina valores socioestilísticos concretos. Así, la opción yo creo que denota un posicionamiento personal que fortalece la carga argumentativa, mientras que la variante morfosintáctica creo que contiene un matiz semántico de posibilidad que reduce el carácter subjetivo y se da en interacciones con menor tensión ideológica (Aijón Oliva y Serrano, 2010). Si estamos tratando el cinismo y el quinismo como actitudes antitéticas, las construcciones que analizamos posteriormente están formadas mediante la alternativa yo creo que acompañada de una subordinada sustantiva.

Asimismo, no solo influye la presencia o ausencia del sujeto, sino que la persona gramatical con la que esté construida la oración hace variar el significado. Benveniste (1966) apuntó que, si este tipo de verbos cognitivos se conjugan en primera persona del singular de la voz activa, el significado implica una actitud personal más fuerte que el significado aportado por otras personas gramaticales del paradigma.

\section{CINISMO Y QUINISMO EN LA MODALIDAD EPISTÉMICA}

El cinismo y el quinismo se materializan con diferente intensidad y, especialmente, en distintas partes del discurso en función de la lengua a la que se privilegie en cada caso. La modalidad epistémica en el grado de opinión puede cumplir dos funciones. Por un lado, una función cínica por cuanto permite a los individuos asumir preceptos hegemónicos y cargar contra el catalán aun sabiendo las consecuencias negativas que sufriría, aquello que denominamos « ritual cínico». Por otro lado, una función quinica en tanto que la expresión lingüística se autocorpora como la resistencia a los axiomas dominantes, lo que hemos venido en denominar «conocimiento quínico». Mediante la perspectiva del ACD, nos proponemos fortalecer en el discurso ese conocimiento quínico que representa la responsabilidad social hacia el catalán frente a un ritual cínico que acepta pasivamente el orden sociolingüístico dominante. Las múltiples opiniones en torno a la idoneidad y la inconveniencia 
de que el castellano y el catalán dominen los espacios sociolingüísticos conducen a las siguientes cuatro estructuras arquetípicas en el discurso:

(1) Yo creo que el catalán no debe aparecer aquí.

(2) Yo creo que el catalán sí debe aparecer aquí.

(3) Yo creo que el castellano no debe aparecer aquí.

(4) Yo creo que el castellano sí deber aparecer aquí.

Como hemos señalado anteriormente, hemos elegido un verbo prototípico que indica un juicio basado en una suposición a partir de datos que se interpretan como veraces. La primera persona del singular con la que se conjuga el verbo añade, por su parte, un matiz semántico de adhesión personal que facilita entender la construcción verbal no como una mera suposición, sino como una actitud militante del emisor. Tras estos elementos, el objeto directo se desarrolla mediante una subordinada sustantiva, de manera que la oración queda configurada con una estructura sintáctica característica de este tipo de verbos (Comesaña, 2002).

Dentro de las cláusulas subordinadas, el castellano y el catalán ocupan, cada uno, los dos extremos ideológicos: la idoneidad y la inconveniencia de acaparar un espacio o uso sociolingüístico determinado. Estas ideologías se materializan a través del verbo deóntico deber modalizado en sus formas afirmativa y negativa para abarcar la totalidad de las opciones. Por último, el adverbio deíctico aqui denota los distintos espacios y usos en los que el castellano y el catalán compiten por su predominio.

En estas proposiciones estandarizadas se perciben los componentes de la tríada discursiva propuesta por van Dijk (2001): el componente cognitivo, representado por el sujeto gramatical que apunta a la introspección del hablante y por un verbo de cognición a partir del que no se asume la certeza de lo que se dice; el componente social, representado por el rema, la información nueva que designa las lenguas y los espacios y usos sociolingüísticos en disputa; y, por último, el propio discurso que media entre los dos componentes anteriores y que construye la fantasía ideológica. Cabe reiterar el carácter arquetípico de estas cuatro soluciones enunciativas, puesto que pretenden ser representativas de la diversidad formal que se encuentra en los múltiples tipos de discursos.

Dependiendo del valor de las cláusulas, ya sean afirmativas o negativas, y del estatus de las lenguas, ya sean dominante o minorizada, las funciones cínica y quinica recaen en diferentes lugares de la enunciación. Estas funciones de la modalidad epistémica presentes en los enunciados anteriores se pueden representar esquemáticamente. Para ello, proponemos cuatro plantillas o esquemas elaborados ad hoc para encauzar el análisis discursivo: 
(1) Yo creo que el catalán no debe aparecer aquí cognición sociedad

conocimiento quínico ritual cínico

(2) Yo creo que el catalán sí debe aparecer aquí cognición sociedad

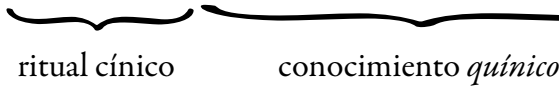

(3) Yo creo que el castellano no debe aparecer aquí cognición sociedad

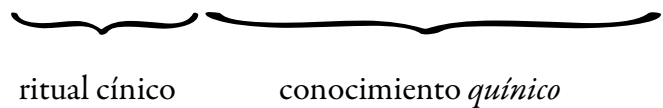

(4) Yo creo que el castellano sí debe aparecer aquí cognición sociedad

conocimiento quínico ritual cínico

Para analizar las estructuras planteadas en los enunciados anteriores, cabe subrayar que el espacio o uso sociolingüístico que denota el deíctico aquí implica la totalidad, o al menos, la mayor parte del escenario simbólico en cuestión.

La proposición (1) simboliza la subordinación del catalán, dado que la ventaja recae sobre el castellano, por lo que existe concordancia estructural entre los pares (1) y (4). El otro binomio de cláusulas, en cambio, restringe el espacio del castellano: en (2), si el catalán es la lengua que, según la ideología de la persona enunciadora, debería aparecer en un ámbito determinado, el castellano quedaría relegado; paralelamente, en (3), si el castellano no debe aparecer en ese contexto, quien ocupa el lugar es el catalán. Por consiguiente, los pares (1) y (4), por un lado, y (2) y (3), por otro, guardan una similitud estructural respecto a las funciones cínica y quinica de sus elementos.

Cuando la persona emisora otorga un rol preponderante al catalán y un rango subordinado al castellano, como se representa en las cláusulas (2) y (3), el compo- 
nente social, que se refiere a la jerarquía sociolingüística de Cataluña, adopta una función quínica en tanto que la actuación o la medida propuesta es contraria a la ideología dominante que defiende la omnipresencia del castellano. Sin embargo, la ideología lingüística patente en estas proposiciones no es totalmente contrahegemónica, porque de haberlo sido, la modalidad epistémica que atenúa la veracidad de la afirmación carecería de sentido y el enunciador habría optado por una marca, también epistémica, pero de un mayor grado de adhesión a la veracidad. Al contrario, en estos dos casos, la modalidad epistémica cumple una función cínica en tanto que existe una lucha interna o cognitiva en el individuo entre un conocimiento quinico que acerca su entendimiento hacia la responsabilidad para con el catalán, y un ritual cínico que refleja la pulsión, leve pero existente, de una ideología dominante que no comparte.

Así pues, la marca de modalidad epistémica juega un rol cínico en (2) y (3) puesto que la matización expresada por yo creo es precisamente la suavización de una ideología lingüística favorable al catalán. En ambos casos, el cinismo recae del lado del saber, del lado cognitivo, por lo que todo intento de luchar contra prejuicios lingüísticos que perjudican al catalán y que están construidos con los esquemas (2) y (3) ha de centrarse en atacar el componente cognitivo de la enunciación del hablante. Si adoptamos el enfoque del ACD para tratar de respaldar la extensión de espacios y usos al catalán, ante afirmaciones estructuralmente equiparables a (2) y (3) como las que se ilustran a continuación, no se debe atacar el componente social sino el cognitivo, ya que este encierra la función cínica y dominante:

(5) Declarándome crítico con políticas de inmersión lingüística como la catalana, yo creo que la Administración debe exigir el conocimiento de las lenguas cooficiales a sus funcionarios (Fernández, 2013)

El referente del ejemplo (5) es la disputa por la aparición del castellano y del catalán en el ámbito del funcionariado público. Si proponemos dotar al catalán de una mayor vitalidad lingüística, previsiblemente aceptaríamos de buen grado la sentencia anterior dado que se le concede la dignidad de ser un requisito en el contexto expuesto. Sin embargo, se puede construir discursivamente una ideología lingüística más favorable para el catalán si se asciende en la escala de la modalidad epistémica y se alcanza un grado de mayor compromiso con la veracidad de la aserción:

(6) Declarándome crítico con políticas de inmersión lingüística como la catalana, ciertamente la Administración debe exigir el conocimiento de las lenguas cooficiales a sus funcionarios. 
El ritual cínico representado en primera instancia por yo creo que - proposición (5) - , que implica la pulsión de la ideología favorable al castellano, queda neutralizado por una fórmula epistémica que promueve una ideología más propicia para el catalán, tal como un adverbio que denota un mayor compromiso con la factualidad de lo expresado que observamos en el ejemplo (6). Como se observa, ante declaraciones del tipo (2) y (3), la fuerza del componente cínico se tiene que compensar utilizando fórmulas epistémicas, como ciertamente, que construyan al emisor con una postura militante en relación a su aserción.

Contrariamente, las proposiciones (1) y (4) sitúan al castellano en una posición ventajosa debido a que el contexto del que se trate quedaría ocupado en buena medida por él. En la estructura oracional de (1) y (4), el ritual cínico recae en ambos casos en el componente social, lo cual indica que las estructuras societales en las que está inmiscuida la persona enunciadora proyectan una fuerte presión que conduce a subordinar el catalán al castellano en un espacio social concreto, tal como los medios de comunicación, la escuela o las interacciones formales, entre otros.

Paralelamente a las oraciones (2) y (3), en los casos de (1) y (4) no se despliega una única ideología, pues de haber sido así, sería más razonable que estas proposiciones estuvieran construidas mediante alternativas que denotasen certeza en las aserciones. El componente social implica una realidad objetivada y, en estos casos, la objetivación ampara los espacios y usos para el castellano, de manera que los privilegios con los que cuenta son promovidos como naturales y de sentido común por parte de diferentes estructuras societales. En cambio, el componente cognitivo ejerce el rol quinico que atenúa esa ideología lingüística. Dentro del sujeto pensante, existen unas configuraciones cognitivas que le llevan a dudar de la ideología que está transmitiendo en su discurso. El grado de opinión de la modalidad epistémica con la que se construyen (1) y (4) evidencia una lucha interna en el individuo en la que sus conocimientos quinicos, como sus intuiciones o cierto tipo de creencias encarnadas discursivamente en el componente cognitivo, cumplen una función de cierto rechazo a la ideología dominante.

$\mathrm{Al}$ igual que en (2) y (3) la presión de la ideología dominante no es suficiente para que la persona enunciadora renuncie a una ideología contrahegemónica de respaldo al catalán, en (1) y (4) la pulsión de la ideología lingüística favorable a esta lengua tampoco es capaz de anular el potencial del ritual cínico. Las marcas modales en estos dos últimos casos funcionan como matizadores de la ideología dominante, de manera que, si el cinismo cae en el componente social, es ahí donde se ha de atacar los prejuicios lingüísticos que subordinan al catalán.

Respecto a la inmersión lingüística en Cataluña, en Pinto Pajares (2018: 290) podemos extraer la siguiente afirmación de una persona entrevistada: 
(7) Me parece discriminatorio y que va contra las libertades y los intereses de los alumnos.

Esta declaración coincide estructuralmente con la cláusula (1) - «yo creo que el catalán no debe aparecer aquí» -, de manera que la parte del discurso que habría que atacar para tratar de construir una ideología lingüística favorable a esta lengua es el componente social, responsable de un ritual cínico. A continuación se proponen algunas alternativas para combatir la ideología lingüística que subordina el catalán en la escuela pública:

(8) $\mathrm{Al}$ alumnado de Cataluña sí le interesa saber catalán porque es una lengua utilizada diariamente.

(9) El Govern, a fi de facilitar a la població no escolar l'exercici del dret i el compliment del deure de conèixer el català, ha de garantir [...] una oferta suficient d'ensenyament del català (Llei 12/2009, Art. 10/4). [El Gobierno, con el objetivo de facilitar a la población no escolar el ejercicio del derecho y el cumplimiento del deber de conocer el catalán, ha de garantizar [...] una oferta suficiente de enseñanza del catalán].

En (8) y (9) se pretende estructurar una ideología lingüística favorable hacia el catalán a partir de la construcción de un nuevo componente social que convierta el ritual cínico de (7) en conocimiento quinico. Si solamente nos centrásemos en modificar el grado de modalidad epistémica y optásemos por una escala más baja, obtendríamos algo como el ejemplo (10):

(10) Quizás sea discriminatoria (la inmersión lingüística en catalán) y vaya en contra de las libertades y los intereses de los alumnos.

Como se observa, atacar el componente cognitivo es ineficaz aun descendiendo el grado de adhesión a la veracidad puesto que el ritual cínico sigue manteniéndose. Más bien, los ejemplos (8) y (9) ofrecen dos alternativas con las que se construye un nuevo sentido común, un conocimiento quinico que concede un espacio social al catalán. En (8) se argumenta que la realidad objetiva en Cataluña exige el conocimiento del catalán, por lo que la inmersión lingüística en esta lengua es de gran provecho para el alumnado. Por su parte, en el ejemplo (9), que procede de un texto legal, se defiende la tesis de que la inmersión en catalán facilita, y no obstaculiza, el correcto ejercicio de los derechos y deberes de toda persona que viva en Cataluña. 


\section{Conclusiones}

En este trabajo se han aplicado dos conceptos cruciales de la obra de Sloterdijk (1989), el cinismo y el quinismo, para elaborar un marco analítico de los discursos en los que el catalán y el castellano son objeto de competencia en los espacios sociolingüísticos de Cataluña. Aunque el catalán goza de alta reputación en la sociedad catalana y de protección institucional, numerosos estudios han demostrado la vulnerabilidad de su uso normalizado. En este contexto, los discursos procedentes de múltiples ámbitos revelan el posicionamiento personal de los emisores a través de marcas ideológicas. Cuando un ámbito social está en disputa entre el castellano y el catalán, la carga ideológica de los discursos puede favorecer o contrarrestar las relaciones asimétricas que se configuran en torno a estas lenguas.

En este trabajo, hemos analizado una serie de construcciones enunciativas arquetípicas que abarcan numerosos dominios en los que el castellano y el catalán luchan por la hegemonía. El enfoque del ACD que hemos seguido nos sitúa en una posición de defensa hacia la lengua catalana al considerar que su convivencia social con el castellano engendra relaciones de poder que lo subordinan. No se trata de analizar particularmente cada escenario político, social o cultural en el que el factor lingüístico puede interceder; más bien, hemos propuesto un marco analítico para detectar en el discurso las ideologías lingüísticas contrarias a la revitalización del catalán y tratar de revertirlas mediante soluciones epistémicas de distinto grado.

Dado que las posibilidades de construcción discursiva son cuantiosas, hemos reducido el espectro a la técnica de la modalidad epistémica en grado de opinión. Mediante esta modalidad discursiva, las personas emisoras asumen cierto compromiso con la veracidad de sus aserciones y, aunque estas no poseen un verificador externo, lo relevante no es el acercamiento a la realidad factual, sino la propia subjetividad de las opiniones que dan información sobre la pulsión de ideologías hegemónicas o contrahegemónicas.

Los enunciados propuestos en (1), (2), (3) y (4) representan una amalgama de opiniones sobre el castellano y el catalán en las que las personas emisoras adoptan una actitud de cierto compromiso hacia la veracidad del contenido de sus aserciones. Este compromiso se materializa en el discurso a través de marcas epistémicas que van desde la posibilidad al convencimiento firme. Concretamente, el grado de opinión permite que se vislumbre en el sujeto una lucha interna a nivel ideológico entre un ritual cínico que le empuja a adoptar la postura oficial de respaldo al castellano y un conocimiento quinico por el que favorece los ámbitos de aparición del catalán.

En este grado de la modalidad epistémica, ambos componentes están presentes, de manera que los hablantes no transmiten una única y clara ideología, sino que 
el compromiso con una de ellas se ve atenuado por la ideología contraria. Detectar en qué parte del discurso se localiza cada ideología es primordial para saber a partir de qué elemento se debe construir un discurso que legitime los espacios y usos concedidos al catalán. Con base en esta delimitación, es necesario reforzar el componente quinico a través de dos estrategias.

Por un lado, cuando la pulsión de la ideología que privilegia al castellano aquello que denominamos ritual cínico- se encuentra en el componente cognitivo del discurso, es decir, en el sintagma que se refiere al proceso mental por el que el emisor se adhiere a su enunciado, es necesario elevar el grado de compromiso para dotar de mayor certeza al contenido de la opinión que, en este caso, respalda la aparición del catalán. Se han de utilizar, por tanto, marcas epistémicas que no den lugar a interpretaciones dubitativas, sino que se adhieran firmemente a la veracidad a la que se refiere el segmento discursivo del componente social. Por otro lado, la actitud cínica puede manifestarse en el fragmento discursivo que hace referencia a distintos ámbitos sociolingüísticos como la legislación sobre las lenguas en Cataluña o la legitimidad del uso del catalán en contextos hegemonizados por el castellano. Como hemos argumentado, atacar en este caso el modalizador epistémico resulta en vano dado que la carga del ritual cínico se encuentra en el propio contenido de la aserción. Por consiguiente, es necesario articular racionalidades alternativas a lo expresado por estas opiniones. En nuestros ejemplos, hemos contradicho las ideologías que favorecen al castellano a través de la búsqueda de razones que demuestran justamente la idoneidad de la presencia del catalán. En este sentido, consideramos que las técnicas argumentativas juegan el principal rol de configuración de nuevas racionalidades.

Las ideologías antitéticas sobre la situación sociolingüística de Cataluña pueden aparecer simultáneamente mediante marcas discursivas. Se torna fundamental, por tanto, discernir las diferentes partes de los discursos elaborados mediante la modalidad epistémica en grado de opinión con el objetivo de detectar en qué segmentos se manifiestan las ideologías dominantes y revertirlas en consecuencia.

\section{Bibliografía}

Aijón Oliva, Miguel A. y María J. Serrano (2010): «El hablante en su discurso: expresión y omisión del sujeto de creo», Oralia: Análisis del discurso oral, 13, pp. 7-38.

Allan, Julie (2004): «The aesthetics of disability as a productive ideology», en Linda Ware (ed.), Ideology and the politics of (in)exclusion, Nueva York, Peter Lang Publishing, pp. 32-45. 
ARndT, Hans (1987): «Speech functions, cooperation and competition in dialogue», en Conference on Language and Power, Bellagio, Italia.

Bastardas, Albert (1986): The Relation Between Linguistic Context, Behaviour and Competence: The Second Generation of Castilian-speaking Immigrants in Non-metropolitan Catalonia, Quebec, International Center for Research of Bilingualism.

Benveniste, Émile (1966): Problèmes de linguistique genérale, vol. I., París, Gallimard.

Borx, Emili (1993): Triar no és trabir. Identitat i llengua en els joves de Barcelona, Barcelona, Edicions 62.

Borx, Emili y Carles De Rosselló (2003): «Les mentalitats lingüístiques de l'estudiantat de la Universitat de Barcelona (2002)», investigación no publicada y encargada por el Vicerrector de Política Lingüística i Relacións Institucionals de la Universitat de Barcelona.

Bretxa, Vanessa y Xavier Vila i Moreno (2012): «Els canvis sociolingüístics en el pas de primària a secundària: el projecte RESOL a la ciutat de Mataró», Treballs de Sociolingüistica Catalana, 22, pp. 93-118.

Calsamiglia, Helena y Amparo Tusón (1980): «Ús i alternança de llengües en grups de joves de Barcelona: Sant Andreu del Palomar», Treballs de Sociolingüistica Catalana, 3, pp. 11-82.

Comesaña, Susana M. (2002): «Los verbos de conocimiento en español», Verba, 29, pp. 243-260.

De SAEgER, Bram (2006): «Evidencialidad y modalidad epistémica en los verbos de actitud proposicional en español», Interlingüistica, 17, pp. 268-277.

Dowling, Andrew (2013): Catalonia since the Spanish Civil War: Reconstructing the Nation, Eastbourne, Sussex Academic Press.

FAIRClough, Norman (2003): Analysing discourse: Textual analysis for social research, Londres, Routledge.

Fernández, María (2013): «El Constitucional avala que el catalán no se exija para opositar en Baleares», El Pais. En línea: https://elpais.com/politica/2013/10/02/actualidad/1380706497_035916.html [13/08/2019].

Halliday, Michael y Christian Matthiessen (2014): Halliday's introduction to functional grammar, Londres, Routledge.

Iglésias, Narcís (2019): «Language Policies in Contemporary Catalonia: A History of Linguistic and Political Ideas», en Pompeu Casanovas, Montserrat Corretger y Vicent Salvador (eds.), The Rise of Catalan Identity: Social Commitment and Political Engagement in the Twentieth Century, Cham, Springer, pp. 79-105. 
Institut d'Estadística de Catalunya (2019): Enquesta d'usos lingüistics de la població 2018, Barcelona, Generalitat de Catalunya.

LASERnA, Mario (1985): «La teoría de la verdad en Kant», Ideas y Valores, 34 (6667), pp. 21-36.

Llei 12/2009, del 10 de juliol, d'educació. Diari Oficial de la Generalitat de Catalunya, núm. 5422, de 16 de julio de 2009.

Mar-Molinero, Clare (1994): «The politics of language: Spain's minority languages », CLE Working Papers, 3, pp. 106-113.

Otaola Olano, Concepción (1988): «La modalidad (con especial referencia a la lengua española)», Revista de Filología Española, 68 (1/2), pp. 97-117.

Pinto Pajares, Daniel (2018): Representaciones ideológicas de las lenguas: análisis comparativo de las ideologías lingüisticas en las clases altas gallega y catalana. Tesis de doctorado. Vigo: Universidade de Vigo.

ShabAD, Goldie y Richard GunTher (1982): «Language, nationalism, and political conflict in Spain», Comparative Politics, 14 (4), pp. 443-477.

Sloterdijk, Peter (1989): Critica de la razón cínica, Madrid, Taurus.

VAn Dijk, Teun A. (2006): «Ideology and discourse analysis. Journal of Political Ideologies $\gg, 11$ (2), pp. 115-140.

VAn Dijk, Teun A. (2004): «Discurso y dominación», Grandes Conferencias en la Facultad de Ciencias Humanas, 4, pp. 5-28.

VAN Dijk, Teun A. (2001): «Multidisciplinary CDA: A plea for diversity», en Ruth Wodak, y Michael Meyer (eds.), Methods of critical discouse analysis, Londres, SAGE, pp. 95-120.

WoDAK, Ruth et al. (2009): The Discursive Construction of National Identity, Edimburgo, Edinburgh University Press.

Fecha de recepción: 20 de noviembre de 2019

Fecha de aceptación:27 de marzo de 2020 